\title{
ЭНДОКРИНОЛОГИЧЕСКИЙ ДИСПАНСЕР МОСКОВСКОЙ ОБЛАСТИ ОНЛАЙН
}

\author{
Древаль А.В. \\ Московский областной научно-исследовательский клинический институт (МОНИКИ), Москва
}

Разработан портал «Эндокринологический Диспансер Московской Области (МО) онлайн» www.enddis.ru для оказания онлайн помощи больным с эндокринными заболеваниями МО, а также эндокринологам МО. В рамках работы портала осуществляется дистанционное консультирование больных (режим «больной-врач») и врачей (режим «врач-врач») МО. Также организуются онлайн Школы больных сахарным диабетом. На портале создана библиотека электронных книг по эндокринологии, которая доступна не только врачам, но и клиническим ординаторам, а также популярные для больных электронные книги. Решаются с помощью портала и организационные вопросы эндокринологической службы МО, которые находятся в ведении главного эндокринолога МО. Например, осуществляется контроль за расходованием лекарственных препаратов, расходных материалов для помповой инсулинотерапии и самоконтроля диабета. Создан раздел для кафедры эндокринологии ФУВ МОНИКИ, через который может осуществляться онлайн-взаимодействие с ординаторами (которых около 60 человек в год, и они находятся на различных областных клинических базах). Представлена также информация о выездной эндокринологической поликлинике (модуль). Таким образом, в настоящее время появились новые удобные инструменты для организации эндокринологической помощи в регионе через онлайн-сервисы. 